\title{
Radioactive Waste Classification, Management and Environment
}

\author{
Md. Iqbal Hosan
}

Department of Nuclear Engineering, University of Dhaka, BANGLADESH

Corresponding Contact:

Email: iqbalhosan@du.ac.bd

\begin{abstract}
Radioactive waste comes from the nuclear power production facilities; defenserelated weapon activities, medical/hospitals use radioisotopes and research activities has a dreadful crisis for management and protecting the environment to be safe to the present and future generations. In this study different types of waste are classified according to international standards, the source of waste is identified around the world and Bangladesh, and waste disposal plan in the world and Bangladesh are analyzed. Although Bangladesh has excellent facilities for the management of present radioactive waste its need improvement for the final disposal of the present and future radioactive waste arise from the country's first nuclear power plant.
\end{abstract}

Key words

Radioactive Waste, Waste Classification, Geological Disposal, Transmutation, Regulations, Policy

$12 / 30 / 2017$

Source of Support: None, No Conflict of Interest: Declared

This article is licensed under a Creative Commons Attribution-NonCommercial 4.0 International License.

Attribution-NonCommercial (CC BY-NC) license lets others remix, tweak, and build upon work non-commercially,

and although the new works must also acknowledge \& be non-commercial.

\section{INTRODUCTION}

Radioactive waste production is increased day by day all over the world and also in Bangladesh. This increase of radioactive waste is because of the various activities of human, nuclear power generation, the different part of the nuclear fuel cycle and for the use of radioactive materials in industry, medicine, agriculture and institutional research. Radioactive waste (or nuclear waste), by definition, "is a material deemed no longer is use that has been contaminated by or contains radionuclide's. Radionuclide's are unstable atoms of an element that decay, or disintegrate spontaneously, emitting energy in the form of radiation" (Radioactive, 2017). For legal and regulatory purposes IAEA's Radioactive Waste Management Glossary defined radioactive waste as "waste that contains or is contaminate with radionuclides at concentrations or activities greater than clearance level as established by regulatory body" (IAEA, 2003).

Radioactive waste mainly produced from the nuclear installations. Every stage of the nuclear fuel cycle radioactive waste is formed. Very big amounts of solid and liquid radioactive waste produce in the mining and milling of uranium ore. In the fuel fabrication process, waste arises from HEPA filters and other dry trash contaminated with UO2. The 
liquid waste stream of oil, water, and traces of UO2 produce before inserting the fuel into the cladding. During reactor operation, radio-nuclides produce from the fission reaction, and isotopes of actinide series produce from the neutron capture reactions in the fuel. The gaseous radio-nuclides release into the atmosphere through filters. The firm waste stream consists of spent ion-exchange resin from primary heat transport system, moderator loop and spent fuel storage bay. Other minor sources of waste include filter sludge, filter cartridges, evaporator bottoms and compactable and non-compactable trash. The compactable trash consists of contaminated clothes, mops, bags, and gloves while the noncompactable trash includes contaminated conduits, instruments and some reactor components. The liquid waste stream from reactors consists of washing, leakage, and solutions used for decontamination processes. The liquid concentrates originate from evaporative volume reduction of contaminated water from the regeneration of resins, decontamination procedures, and active chemical waste (FIS, 1999).

Highly radioactive liquid waste comes from the fuel reprocessing. The significant amount of noble gas fission products release into the atmosphere during reprocessing.

\section{Classification of Radioactive Waste}

Radioactive waste classification derived from different points of view such as safety-related aspects, processing engineering demands or regulatory issues. At the conceptual level, operation level and also for communication purposes classification of radioactive waste may be helpful. At any stage between the arising the raw waste and its conditioning, interim storage, transportation, and disposal waste classification are significant. Based on the purpose of a radioactive waste categorization system there exist different approaches to its derivation (IAEA, 1992; Rao, 2001). One way is based on the qualitative description of a general class of radioactive waste and another way is quantitative which gives numerical values for the definition of different group of waste.

\section{Qualitative Approach}

In this approach, wastes are classified regarding their origin and physical state. The consideration for beginning includes the different stage of the nuclear fuel cycle (such as mining and milling, fuel supply, reactor operations / power generation, management of spent of spent fuel) and production and use of radionuclides (research activities, radioisotope production, and radioisotope applications) (IAEA, 1994). The physical state consideration includes solid waste, liquid waste, and gaseous waste (Mishra, 1999).

\section{Quantitative approach}

In quantitative approach, liquid waste is classified into five classes based on their concentration level. Class 1 waste comprises beta, gamma radionuclides with concentrations < $10-6$ microCi/ml $(<3.7 X 104 \mathrm{~Bq} / \mathrm{m} 3)$. Class 1 waste is not normally treated and discharged directly into the nearby atmosphere. Class 2 waste comprise radionuclides with concentration in the range $>10-6$ to $<$ 10-3 microCi/ml $(>3.7 X 104$ to $<$ 3.7X107 Bq/m3). This type of waste sent to the effluent treatment plant (ETP) for treatment (IAEA, 1992), and no shielding is necessary. Class 3 waste comprise radionuclides with concentrations $>10-3$ to $<\_10-1 \mathrm{microCi} / \mathrm{ml}(>3.7 \mathrm{X} 107$ to $<3.7 \mathrm{X} 109 \mathrm{~Bq} / \mathrm{m} 3)$. This class waste sent to ETP for treatment under shielding conditions. Class 4 waste comprises radionuclides with concentrations $>10-1$ to $<$ 104 microCi/ml (>3.7X109 to $<$ 3.7X1014). This waste treat just like as class 3. Class 5 waste comprises radionuclides which concentration are $>104 \mathrm{microCi} / \mathrm{ml}(3.7 \mathrm{X} 1014 \mathrm{~Bq} / \mathrm{m} 3)$. This type of waste is store in underground steel tanks under cooling conditions (Mishra, 1999; IAEA, 1970). 
Solid waste is classify into 4 class based on radiation dose on the surface of the package. Class 1 waste comprises the beta and gamma emitters, and an insignificant amount of alpha whose radiation level on the surfaces is $<$ _0.2 $\mathrm{R} / \mathrm{hr}(2 \mathrm{mGy} / \mathrm{hr})$. Without any special precautions, this type of waste can be handled and transported. Class 2 waste comprises the beta and gamma emitters, and an insignificant amount of alpha whose radiation level on the surface is $>0.2$ to $<22$ $\mathrm{R} / \mathrm{hr}(>2 \mathrm{to}<20 \mathrm{mGy} / \mathrm{hr})$. These waste are transported in simple containers shielded with a thin layer of concrete or lead. Class 3 waste comprises the beta and gamma emitters, and an insignificant amount of alpha whose radiation level on the surface is $>2 \mathrm{R} / \mathrm{hr}(>20 \mathrm{mGy} / \mathrm{hr})$. This type of waste is handled and transported with special precautions. Class 4 waste comprises dominant alpha emitters and an insignificant amount of beta and gamma emitters. The activity of this waste expresses in $\mathrm{Ci} / \mathrm{m} 3(\mathrm{~Bq} / \mathrm{m} 3)$. This waste is disposed of in trenches/tile holes if the alpha activity is very low while the waste having higher concentrations are stored above the surface or in tile holes with the intention of retrieval (FIS, 1999; IAEA, 1992).

In many countries the significance of classifications gaseous waste is debatable. Generally, gaseous wastes are classified into three classes. Class 1 waste comprises radionuclides which concentrations is $<$ _ $10-10 \mathrm{Ci} / \mathrm{m} 3(3.7 \mathrm{~Bq} / \mathrm{m} 3)$. This class waste is discharged directly into the atmosphere without any treatment. Class 2 waste comprises radionuclides which concentrations is $>10-10$ to $<\_10-6 \mathrm{Ci} / \mathrm{m} 3$ (>3.7 to $<$ _3.7X104 Bq/m3). After simple filtration, this type of waste is discharged into the atmosphere. Class 3 waste comprises radionuclides which concentrations is $>10-6 \mathrm{Ci} / \mathrm{m} 3(3.7 \times 104 \mathrm{~Bq} / \mathrm{m} 3)$. This type of waste treated with a combination of absorption and filtration techniques. (Mishra, 1999; IAEA, 1970)

Both the qualitative and quantitative approach to waste classification lead to six classes of waste (IAEA, 2009). The radioactivity level of these wastes range from very negligible to very high concentration of radionuclides; with decay, period varies from tens of years to few million years. There is an increased need to isolate them from reaching biosphere through suitable disposal options that may range from simple earth trench too deep underground geological repository.

\section{Exempt waste (EW)}

Exempt waste have such little concentrations of radionuclides that it does not require requirements for radiation protection, irrespective of whether the waste is disposed of in conventional landfills or recycled. This type of waste is cleared from regulatory control and does not require any further contemplation from a regulatory control viewpoint (IAEA, 2009a).

The values of activity concentration for artificial radionuclides resulting on the basis of generic scenarios for the recycling and clearance of waste: "The primary radiological basis for establishing values of activity concentration for the exemption of bulk amounts of material and clearance is that the effective doses to individuals should be of the order of $10 \mu \mathrm{Sv}$ or less in a year. Taking the considerations of the occurrence of low probability events leading to higher radiation exposures, an additional measure use, namely, the effective doses for such low probability events should not go beyond one mSv in a year. (IAEA, 2009a) In this case, consideration also given to doses to the skin; an equivalent dose criterion of $50 \mathrm{mSv}$ in a year to the skin used for this purpose. This approach is consistent with that used in establishing the values for an exemption provided in Schedule I of the BSS" (IAEA, 2004).

\section{Very short-lived waste (VSLW)}

Very short lived waste has only radionuclides of very short half-life with activity concentrations above the authorization levels. This type of waste waste can store up until 
the activity has fallen under the margins of clearance, allowing for the cleared waste to manage as usual waste. The major criteria for the categorization of waste as VSLW are the half-lives of the predominant radionuclides and the suitability of the amounts of longer halflife radionuclides. However, in general, the supervision option of storage for decay is applied for waste containing radionuclides with half-lives of the order of 100 days or less (IAEA, 2009a). Through radioactive decay, VSLW will move into the class of exempt waste.

\section{Very Low-Level Waste (VLLW)}

Considerable amounts of waste arising from the operation and decommissioning of nuclear facilities with levels of activity concentration in the region of or slightly above the margins specified for the permission of material from regulatory control (IAEA, 2009a). Waste with such a limited hazard, which is nevertheless above or close to the values for exempt waste, is called very low-level waste. A satisfactory level of safety for VLLW achieved by its disposal in engineered surface landfill type facilities. This engineered surface landfill type facility is the usual practice for hazard from some mining operations and other waste containing naturally occurring radionuclides from various operations involving minerals processing and other activities. Some States also use this disposal method for waste with low levels of activity concentration arising from nuclear installations (ADSN, 2005; IFO, 2005; IAEA, 2009a).

\section{Low-Level Waste (LLW)}

Low-level waste is waste that is appropriate for near-surface disposal. This near-surface disposal option is appropriate for waste that contains such an amount of radioactive material that robust containment and isolation for short period of time up to a few hundred years are required. This class covers a very large range of radioactive waste. It ranges from radioactive waste with an activity content level just above that for VLLW, that is, not requiring shielding or particularly robust containment and isolation, to radioactive waste with a margin of activity concentration such that shielding and more robust containment and isolation are essential for periods up to several hundred years (IAEA, 2009a). The regulatory body should create limits for the disposal of long-lived radionuclides by the safety assessment for the particular disposal facility. A limit of $400 \mathrm{~Bq} / \mathrm{g}$ on average (and up to $4000 \mathrm{~Bq} / \mathrm{g}$ for individual packages) for long-lived alpha-emitting radionuclides has been adopted in some States (CFR, 1992; French, 1984; Kim, 1996; IAEA, 2009a).

\section{Intermediate level waste (ILW)}

This type of waste contains long-lived radionuclides in quantities that need a containment and separation from the biosphere that is provided by near-surface disposal. Disposal in a facility at a depth of between a few tens and a few hundreds of meters specify for ILW. Disposal at such depths has the potential to give a period of isolation from the accessible environment if both the natural barriers and the engineered barriers of the disposal system are selected. In particular, there is no unfavorable effect of erosion at such depths in short to medium term. An additional benefit of disposal at intermediate depths is that, in contrast to near-surface disposal facilities appropriate for LLW, the possibility of inadvertent human interruption reduce. Consequently, long-term safety for disposal facilities at such intermediate depths will not depend on the application of institutional controls (IAEA, 2009a).

\section{High-level waste (HLW)}

If large concentrations of both short and long-lived radionuclides that, compared to ILW present in a waste then it is called high-level waste. Containment and isolation from the accessible environment is needed to ensure long-term safety. This type of containment and 
isolation are generally provided by the integrity and stability of deep geological disposal, with engineered barriers. HLW generates noteworthy quantities of heat from radioactive decay and continues for a number of centuries. Heat dissipation is a significant factor that has to take into account in the design of geological disposal facilities. HLW usually has levels of activity concentrations in the range of 104-106 TBq/m3 (IAEA, 2009a).

\section{Radioactive Waste Produced in Bangladesh}

The radioactive waste produced from the nuclear power production, different medical centers, research organizations and industries which use radioactive material requires longterm management plan (IAEA, 2005). The research facility of Bangladesh is Atomic Energy Research Establishment (AERE) under Bangladesh Atomic Energy Commission (BAEC), in Savar, located $45 \mathrm{~km}$ south-west of the capital city Dhaka. In this research facility, there are a BAEC TRIGA Research Reactor (BTRR), (Hosan et al., 2015) Radioisotope Production Laboratories, a $14 \mathrm{MeV}$ neutron generator, one Tandem Accelerator and two 60Co irradiators (350 kCi in 2010 and $65 \mathrm{kCi}$ in 2009). Under BAEC there are 18 nuclear medicine centers/departments, 12 60Co radiotherapy facilities, two gamma-ray irradiator facilities, 11 linear medical accelerators, one Van de Graff generator, three 192Ir high dose rate (HDR), two dose rate (LDR) brachytherapy units and several 192Ir industrial radioactive sources working in the country (Mollah et al., 2016). Also Universities/Colleges, Hospitals, Bangladesh Institute of Nuclear Agriculture, Private Nuclear medicine centers and industries also use different radioactive materials (Mollah et al., 1993; Mollah, 2005a; Mollah, 2005b; Mollah, 2005c; Mollah, 2005d; Mollah, 2012; Mollah and Aleya, 2005; Mollah, 2009). The present sources of radioactive waste in Bangladesh shows in Fig. 1. These entire radioactive sources use for a variety of purposes in research, medicine, industry and other fields. A significant amount of liquid, solid, gas and mixed radioactive waste including sealed radioactive waste (SRS) produce from these activities. At present, there is no nuclear power plant (NPP) in Bangladesh, so the radioactive waste is mainly coming from the radioactive source used in the various activities mentioned in Fig. 1.

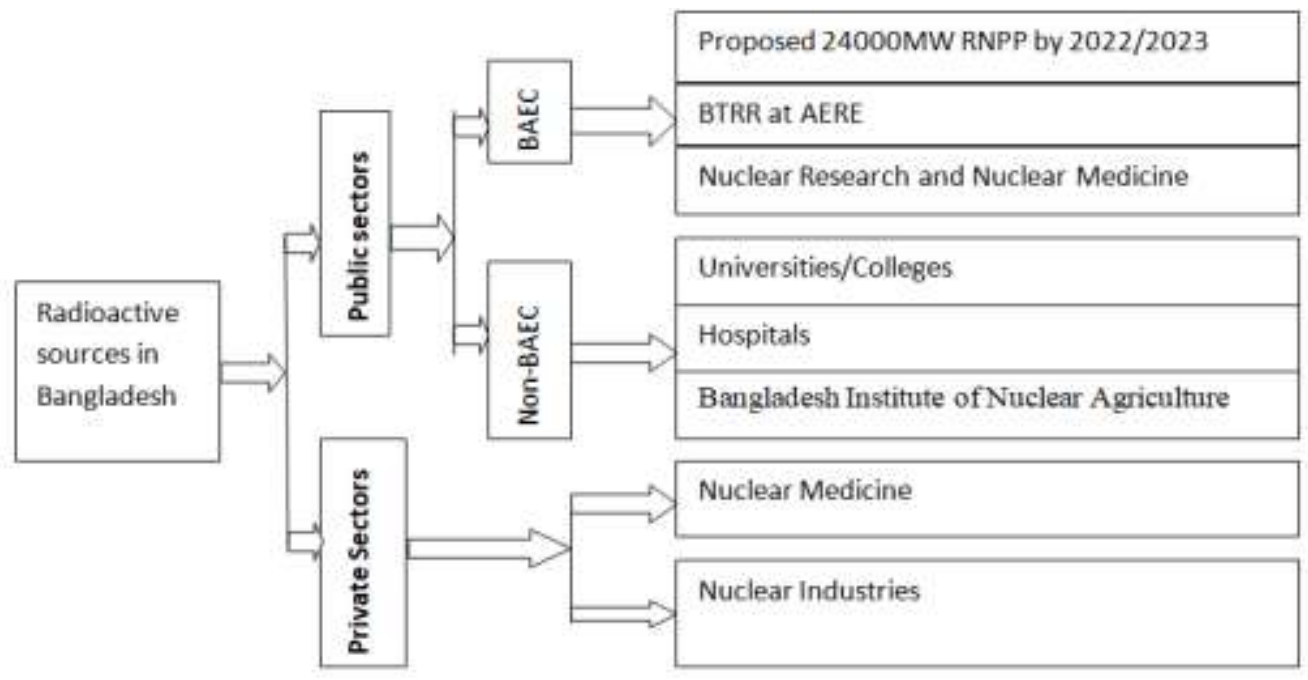

Figure 1: Present source of radioactive waste in Bangladesh (Mollah et al., 2016)

However, Bangladesh government is now planning for generation of electricity from the nuclear power plant and recently they have taken a project called Rooppur Nuclear Power 
Plant Project (RNPP) (Mollah et al., 2015) which is going to be operated by 2022/2023. Nuclear energy and ionizing radiation utilization in Bangladesh are comparable with that of other developing countries in the world. The radioactive waste management comprises of treatment, conditioning, storage, transportation and final disposal of the high-level waste. This should be in such a manner that can protect human health and environment without imposing undue burdens on the future generations.

\section{Waste Disposal Methods Around the World}

At present 448 nuclear power reactors are operated with total net installed capacity of 391744 MW over the world. Also there are 58 reactors are under construction worldwide (IAEA, 2017). From the total operated reactor, as a part of the nuclear fuel cycle, radioactive wastes are produced regularly. It should be kept in mind that the half-life of certain radioactive waste is in the range of 500,000 years or more (Ewing, 1999). To avoid the permanent damage of the surrounding environment it is necessary to handle the waste safely. The waste produced from this facility can be temporarily treated on site using verification, ion exchange or sync method. For the safe use of nuclear power long-term management is necessary. There are several specific long-term management methods using all over the world. This method includes geological disposal, transmutation, waste re-use and space disposal.

\section{Geological Disposal}

Geological disposal methods suggested that find a point in the underground for burrowing the nuclear waste which is out of human reach. Several measures should be taken to keep the waste in the ground which includes it should be properly protected to stop any material leaking out, check the burial location is above or below the water level to avoid seepage, protective measures need to be taken to keep in mind the seismic event that can cause immediate contamination and during the long half-life of the radioactive waste how it'll behave in the ground. A major concern for such geological disposal is terror attack (Murray and Manke, 2003).

The United States government proposed a geological disposal project named Yucca Mountain nuclear waste repository for the long-term waste disposal. The federal government has voted to build up the site for future nuclear storage space. Even though the Obama administration has been obdurate in stating that Yucca Mountain is "off the table," Congress voted by a edge of 10 to 1 in 2009 to keep funding the project as part of the federal budget. A number of concerns surround this project and the ultimate long-term practicability of it are yet to be seen given the political ambiguity surrounding it (Macfarlane, 2003).

\section{Reprocessing}

For long-term management of the nuclear waste reprocessing is one of the feasible options throughout the world. In this process, fissionable materials are separated from the irradiated nuclear fuel. These are then sent to the nuclear fuel cycle and others are treated safely. In the reprocessing process, major concern around the world is the nuclear proliferation, and how much easier reprocessing would allow fissionable material to spread (Andrews, 2008).

\section{Transmutation}

Now a day's transmutation also is a process for long-term management of nuclear waste. In this process, the radioactive nuclear element converts into another element which is less harmful than the previous one. Some examples include conversion of Chlorine to Argon, Potassium to Argon, etc. The driving force for this process comes from external spur (proton hitting the reaction material). Natural transmutation also occurs by keeping the waste in the 
geological storage for a long time to become the non-fissionable material that poses little or no risk (Charalambous, 1971).

\section{Space Disposal}

Another option for long-term waste disposal is the space disposal of waste but it is not a feasible option. In this process, nuclear waste are kept in a space shuttle and launching the shuttle into the space. In a single shuttle, a small amount of waste could be shipped compared to the total waste need to be dealt with. This option has some problem from the viewpoint of both practicality and also the economic point (Coopersmith, 2005).

\section{Radioactive Waste Management in Bangladesh}

Radioactive waste management is defined by the Joint Convention on the Safety of Spent Fuel Management and on the Safety of Radioactive Waste Management (IAEA, 1997). This Convention makes the division between radioactive waste management and spent fuel management. Radioactive waste management means all activities, including decommissioning relative to the handling, pre-treatment, treatment, storage or disposal of radioactive waste, excluding off-site transportation. It may also involve discharges (Alexander, 1997). Spent fuel management means all the activities that relate to the handling/storage of spent fuel, excluding offsite transportation. It may also involve discharges (IAEA, 2003). The objective of radioactive waste management is reflected in the joint convention and in the fundamental safety principles developed by the IAEA (IAEA, $2009 b$ ). Spent nuclear fuel and radioactive waste contain a high amount of risk; this is why management requires regarding technical, professional and financial provision of services. Regulatory supervision and approval by the national nuclear regulatory authority are necessary for the utilization of production of energy, ionizing radiation, and radioactive waste management. For the protection of human health and the environment in the present time and also for the future generation a solution is required for the disposal of the radioactive waste.

In this regard, the policy and strategy on radioactive waste and spent fuel management has been drafted for Bangladesh on 2011 based on the Joint Convention on the Safety of Spent Fuel Management and the Safety of Radioactive Waste Management (IAEA, 1997) and Policies and Strategies for Radioactive Waste Management (IAEA, 2009b) with the following objectives (Mollah et. Al., 2016):

- To establish tactically justified, scientifically, technically, environmentally, financially and socially acceptable principles for radioactive waste and spent nuclear fuel management in Bangladesh;

- To build up a basic structure for the decision-making of those authorities and organizations responsible for radioactive waste or spent nuclear fuel management in Bangladesh; and

- To communicate in straightforward way information concerning the long-term management of radioactive waste and spent nuclear fuel to organizations involved in this field and to the general public.

Currently, In Bangladesh, There is only one center that can treat the radioactive waste in the form of the liquid, spent resin, combustible waste and sealed waste (Mollah et al., 1998). The center is the Central Radioactive Waste Processing and Storage Facility (CWPSF) at the Atomic Energy Research Establishment (AERE) under the Bangladesh Atomic Energy Commission (BAEC). The CWPSF equipped with the compactor, chemical treatment, 
conditioning facilities for spent sources and also interim storage. The general radioactive waste management scheme at CWPSF given in Fig.2 (a) and (b).

The present infrastructure for the management of radioactive waste in Bangladesh is not sufficient for the disposal of the existing and future radioactive waste. Improvement is required in the countries legislation and also in the nuclear regulatory law and strategy. Many factors have to be developed in anticipation of the incoming naturally occurring radioactive materials (NORM) and technically enhanced naturally occurring radioactive materials (TENORM) waste along with radioactive wastes from coming Rooppur Nuclear Power Plant operation. Though there is no standard on the infrastructure of radioactive waste management in the world (IAEA, 1994); on the other hand, knowledge from the nuclear power countries shows the similarity on how the radioactive waste can be managed to ensure the safety of the public, the workers, the environment and also the future generations. The general institutional infrastructure at least consists of legislation, regulatory authority and implementing organization, but some developing countries may add funding system and involvement of the stakeholders (IAEA, 2006).

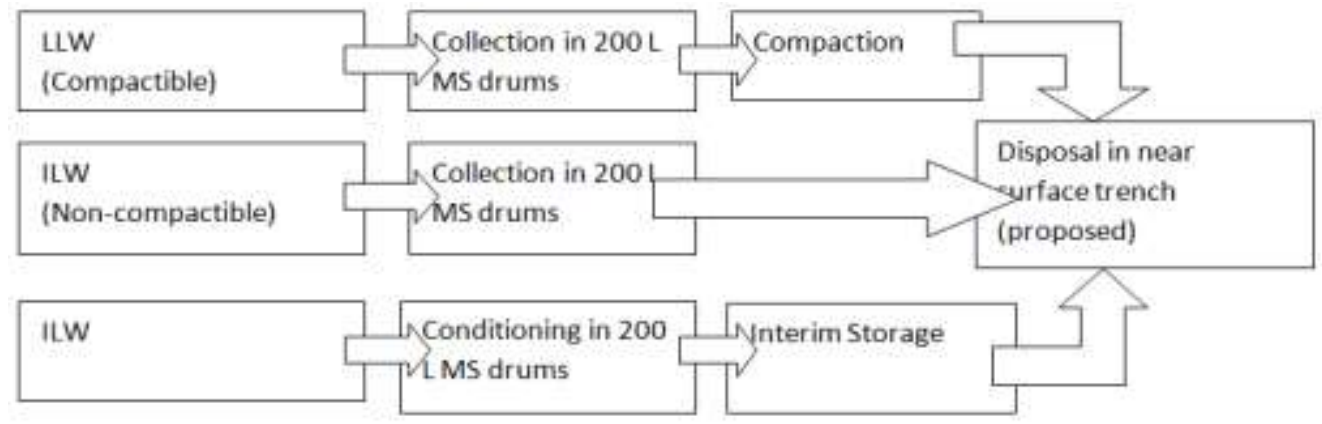

Figure 2 (a): General waste management scheme at CWPSF (Solid waste) (Mollah et al., 2016)

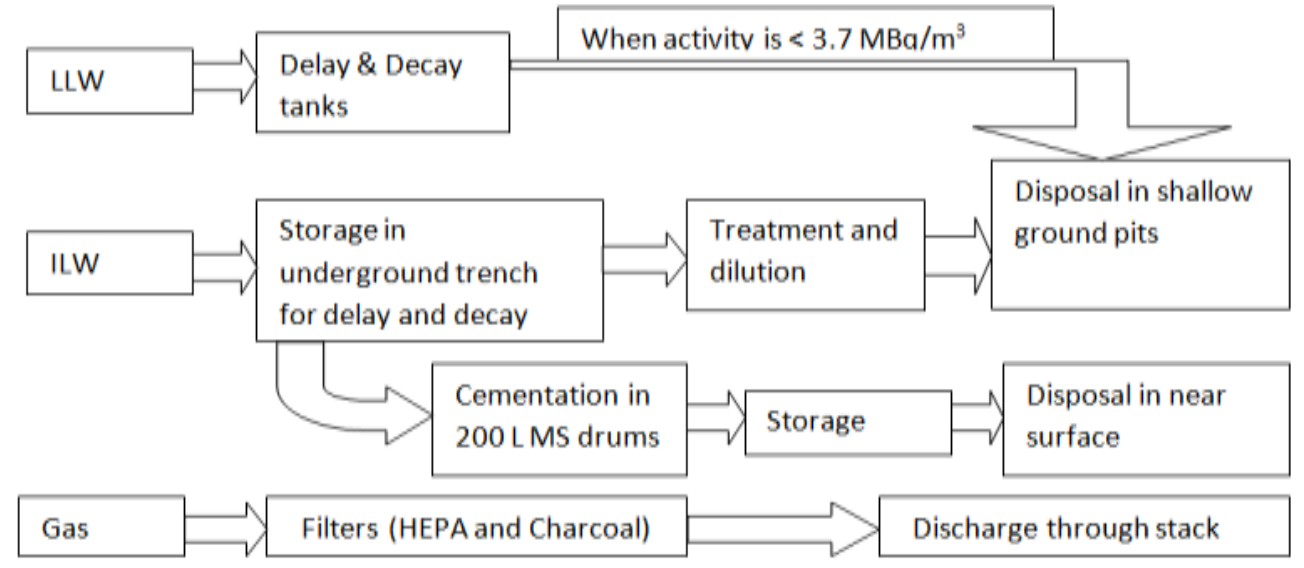

Figure 2 (b): General waste management scheme at CWPSF (liquid and gaseous waste)

\section{CONCLUSION}

Bangladesh is going to build a nuclear power plant by the year 2022/2023, so waste management is a prime concern. Various type of waste produce from the nuclear power plant that needs to be handled with extra care with internationally agreed principles and standards to protect human 
health and the environment now and in the future. The problems associated with radioactive waste management on a long-term are major ones that humanity has not been able to come to terms with so far. Various methods exist for the disposal of nuclear waste. In view of the fact that, waste is a reality with nuclear power so it needs to take in hand accurately to assess the longterm possibility of this power source. Bangladesh should choose the best options for the management of nuclear waste that will be produced from the newly build nuclear power plant.

\section{REFERENCES}

A. Andrews, "Nuclear Fuel Reprocessing: U.S. Policy Development," CRS Report for Congress RS22542, 27 March (2008)

A. Macfarlane, "Underlying Yucca Mountain: The Interplay of Geology and Policy in Nuclear Waste Disposal," Social Studies of Science 33, 783 (2003)

A. S. Mollah and Aleya Begum, "Regulatory and organizational framework for safe management and disposal of radioactive waste in Bangladesh," International Conference on the Safety of Radioactive Waste Disposal, (3 7 October, Tokyo, Japan, 2005), IAEA-CN-135/11, 38, 47-52 (2005d)

A. S. Mollah, "National program and regulatory requirements for the radioactive waste management in Bangladesh," International Conference on Environmental Remediation and Radioactive Waste Management, (September 3-8, Glasgow, Scotland, 2005) ICEM'05-1218 (UK) (CD ROM) (2005a)

A. S. Mollah, "Regulations, Policies, and Strategies for LLRW Management in Bangladesh," Waste Managment Conference WM2012 4, 2935 (ISBN: 978-1-62276-308-5, February 26 - March 1, Phoenix, USA (2012)

A. S. Mollah, "Regulatory Guide on Radiation Protection in Radioactive Waste Management Practices," Nuclear Safety and Radiation Control-WM-G-01, ISBN 984-32-2623-2 (2005b)

A. S. Mollah, "Regulatory Report on Environmental Impact Assessment on Radioactive Waste Management Situation in Bangladesh," Nuclear Safety and Radiation Control Division-TRS-02, ISBN 984-32-2860-X (2005c)

A. S. Mollah, Aleya Begum, M. M. Rahman, "Removal of Radionuclides from Low-level Radioactive Liquid Wastes by Precipitation," J. of Radioanal. Nucl. Chem. 229(1-2), 187 (1998)

A. S. Mollah, M. M. Rahman, "Radioactive waste management and practice in Bangladesh," International Conference on Nuclear Waste Management and Environmental Remediation (September 5-11, Prague, Czech Republic, 1993), ASME 3, 617(1993)

A. S. Mollah, Sabiha Sattar, M. A. Hossain, A.Z.M. Salahuddin and H. AR. Rashid, "Prospects of Nuclear Energy for Sustainable Energy Development in Bangladesh," IJNESE 5, 28-39 (2015)

A. S. Mollah, Sabiha Sattar, M. Altab Hossain, M. H. Jahangir, A.Z. M. Salahuddin, "Analysis of the Institutional Framework for Radioactive Waste Management in Bangladesh," Journal of Nuclear Sciences, Volume 3, No. 2, 35-44 (2016)

A. S. Mollah, “Overview of Regulatory Control for Radioactive Sources and Nuclear Materials for Peaceful Applications of Nuclear Technology," Int. J. of Nuclear Law 2(3), 175 (2009)

Alexander Gillespie, International Environmental Law Policy and Ethics, OUP, p.112. (1997)

Authorité de sûreté nucléaire (ADSN), Joint Convention on the Safety of Spent Fuel Management and the Safety of Radioactive Waste Management: Second National Report on Implementation by France of its Obligations under the Convention, ASN, Paris (2005)

Code of Federal Regulations (CFR), Title 10, Part 61, "Licensing Requirements for Land Disposal of Radioactive Waste," (1992)

First International Seminar (FIS), ASFE'9, on Safety and Fire Engineering, Cochin, India, November 24-26 (1999)

French ministry for industry and research, Surface Centres for Long-Term Disposal of Radioactive Waste with Short or Medium Half-Life and with Low or Medium Specific Activity, Basic Safety Regulations, Regulation No. I.2., Paris (1984)

International affairs office (IFO), nuclear and industrial safety agency, Joint Convention on the Safety of Spent Fuel Management and the Safety of Radioactive Waste Management: National Report of Japan for the Second Review Meeting, METI, Tokyo (2005) 
International Atomic Energy Agency (IAEA) “Involvement in Nuclear Issues," International Nuclear Safety Group, Stakeholder INSAG-20, IAEA, Vienna (2006)

International Atomic Energy Agency (IAEA), "Joint Convention on the Safety of Spent Fuel Management and the Safety of Radioactive Waste Management," INFCIRC/546, IAEA, Vienna (1997)

International Atomic Energy Agency (IAEA), “Management of Waste from the Use of Radioactive Material in Medicine, Industry, Agriculture, Research and Education," IAEA Safety Standards Series No. WS-G2.7, IAEA, Vienna (2005)

International Atomic Energy Agency (IAEA), "Policies and Strategies for Radioactive Waste Management," Nuclear Energy Series No. NW-G-1.1, IAEA, Vienna (2009b)

International Atomic Energy Agency (IAEA), "Power Reactor Information Systems Database," update on 2017-11-06 (2017)

International Atomic Energy Agency (IAEA), "Reference Design for a Centralized Waste Processing and Storage Facility," TECDOC-776, IAEA, Vienna (1994)

International Atomic Energy Agency (IAEA), Application of the Concepts of Exclusion, Exemption and Clearance, IAEA Safety Standards Series No. RS-G-1.7, IAEA, Vienna (2004)

International Atomic Energy Agency (IAEA), Classification of radioactive waste, SAFETY SERIES No. 111G-1.1, IAEA, Vienna (1994)

International Atomic Energy Agency (IAEA), Classification of Radioactive waste, General Safety Guide, IAEA Safety Standards Series No. GSG-1, IAEA, Vienna (2009a)

International Atomic Energy Agency (IAEA), Minimization, and segregation of Radioactive Waste, IAEATECDOC-652, IAEA, Vienna (1992)

International Atomic Energy Agency (IAEA), Radioactive waste management glossary Vienna, p. 48 (2003)

International Atomic Energy Agency (IAEA), Standardization of Radioactive waste categories, Technical Reports Series No. 101, IAEA, Vienna (1970)

J. Coopersmith, "Nuclear Waste Disposal in Space: BEP's Best Hope?" AIP Conference Proceedings 830, 600 (2005)

K. R. Rao, "Radioactive waste: The problem and its management," current science, vol. 81, no. 12, 25 December (2001)

KIM, J.I., et al., German approaches to closing the nuclear fuel cycle and final disposal of HLW, “Corrosion Behavior of Spent Fuel" (Proc. Int. Workshop Überlingen, 1995), J. Nucl. Mater. 238, 1-10 (1996)

MI Hosan, MAM Soner, KA Kabir, MA Salam, MF Huq, "Study on neutronic safety parameters of BAEC TRIGA research reactor," Annals of Nuclear Energy 80, 447-450 (2015)

R. C. Ewing, "Nuclear Waste Forms for Actinides," Proc. Natl. Acad. Sci. 96, 3432 (1999)

R. L. Murray and K. L. Manke, Understanding Radioactive Waste, Battelle Press, (2003)

Radioactive Waste. Pollution A to Z. Encyclopedia.com http://www.encyclopedia.com/ environment/educational-magazines/radioactive-waste, October 24 (2017)

S. Charalambous, "Nuclear Transmutation by Negative Stopped Muons and the Activity Induced by the Cosmic-Ray Muons," Nucl. Phys. A 166145 (1971)

Subhan Ali, "Nuclear Waste Disposal Methods," Submitted as coursework for Physics 241, Stanford University, Winter (2011)

U.C. Mishra, "Nuclear waste management and the environment," First international seminar, SAFE'99, on safety and fire engineering, Cochin, India, 24-26, (1999)

ISSN: 2409-3629

Online Archive Link: https://abc.us.org/ojs/index.php/ei/issue/archive 